\title{
Cognitive-Behavioral Group Treatment for Men Voluntarily Seeking Help for Violence towards Their Intimate Partners: The Impact of Treatment Components 4 - 7 Years after Therapy
}

\author{
Stig Jarwson*, Merete Berg Nesset, Tom Palmstierna, Jim Aage Nottestad, Erik Søndenaa \\ St. Olavs Hospital, Forensic Department Brøset, Norwegian University of Science and Technology, Norway \\ Email: stig.jarwson@stolav.no
}

Received 3 July 2015; accepted 25 September 2015; published 28 September 2015

Copyright @ 2015 by authors and Scientific Research Publishing Inc.

This work is licensed under the Creative Commons Attribution International License (CC BY).

http://creativecommons.org/licenses/by/4.0/

(c) (i) Open Access

\begin{abstract}
Background: Even though domestic violence is a major problem, only a few studies have examined the long term sustainability of treatment for men who voluntarily seek help to stop their violent behavior towards intimate partners. Women are exposed to a much greater degree of serious violence and sexual abuse compared to men. Objective: The aim of this study was to identify which elements of the treatment program batterers found most useful four to seven years after program completion. Design: The participants consisted of a sample of men who had gone through anger management therapy four to seven years previously. Data on violence were collected through selfreport before and four to seven years after treatment, using a modified version of the Conflict Tactics Scales. Results: The decrease in physical violence was statistically significant: $t(36)=8.43, p<$ 0.001 with a large effect size (eta squared $=0.66$ ). Psychological violence also decreased significantly: $t(36)=9.21, p<0.001$ with a large effect size (eta squared $=0.7$ ). The results indicate that the most important anger management techniques were extensively applied in former patients of the anger management treatment program. In total, about two out of three patients still used the techniques after ending treatment four to seven years earlier.
\end{abstract}

\section{Keywords}

Intimate Domestic Violence, Cognitive Behavioral Treatment, Cognitive Techniques

\footnotetext{
${ }^{*}$ Corresponding author.

How to cite this paper: Jarwson, S., et al. (2015) Cognitive-Behavioral Group Treatment for Men Voluntarily Seeking Help for Violence towards Their Intimate Partners: The Impact of Treatment Components 4 - 7 Years after Therapy. Open Journal of Nursing, 5, 836-842. http://dx.doi.org/10.4236/ojn.2015.59088
} 


\section{Introduction}

Research on the effectiveness of treatment programs for partner-violent men has yielded mixed findings. In their evaluation of meta-analyses and experimental designs, Gondolf and Jones (2001) found little or no treatment effect. The studies included three, well-established batterer programs using a gender-based, cognitive-behavioral approach $(n=640)$. Completing a batterer program reduced the men's likelihood of re-assaulting by a percentage ranging from $44 \%$ to $64 \%$, depending on the specifications used. Completing a 3-month program appeared to be as effective as completing a 5.5- or 9-month program [1]. In a recent Cochrane report [2], it was stated that in spite of many studies on the treatment of domestically violent men, the evidence of controlled studies is insufficient to draw conclusions on the effects. He also noted that most studies focused on the treatment of courtordered clients and that many studies lacked a description of the actual content of the therapy.

A meta-analysis of 50 studies with a total of 1640 clients was conducted to determine whether cognitive therapy was an effective treatment of aggression and hostile power dominance [3].

Patient groups studied included abusive parents and abusive spouses, school children, clinical adolescents, juvenile delinquents, inmates, and college students. Effect sizes were calculated from self-reports of anger, dependent measures of anger and aggression, and behavioral ratings of aggression, and they were averaged across variables to produce one effect size per study. The effect sizes for the 50 studies ranged from -0.32 to 1.57 (SD 0.43) with all effect sizes but one being positive in value. The grand mean weighted effect size was 0.70 ( $p<$ 0.001), which means that the average patient who received CBT fared better than $76 \%$ of the patients who did not receive CBT. This corresponds to a treatment success rate of $67 \%$ for CBT compared with $33 \%$ for patients who received control treatments.

A study of the Brøset Model [4] showed that a 15-week manual, group-based CBT program significantly and substantially reduced self-reported violent behavior. After the initial assessment but before group therapy sessions, 26 men were randomly selected for immediate treatment or put on a waiting list.

In the treatment group, all kinds of self-reported partner-related violence were significantly reduced, while those on the waiting list did not reduce their partner-related violence. The results indicate that the group treatment had an effect in itself beyond the wishes and intentions of the men to reduce their partner violence.

\section{Aim}

The aim of this study was to identify which elements of the treatment program batterers found most useful four to seven years after program completion.

\section{Methods}

\subsection{Subjects}

Over a period of four years, 269 men completed the Cognitive behavioral group-treatment "Brøsetmodellen" (see below). A randomized sample of 85 men were selected and asked by mail to respond to a questionnaire as part of a follow-up study, concerning their current use of violence and use of the techniques from their treatment sessions. Ten of the eighty-five men were not traceable. Of the remaining seventy-five, four were unwilling to participate. From this sample $(n=71) 37$ (52.1\%) participated and 34 (47.9\%) did not. A demographic comparison between the responders and the non-responders did not confirm any differences in age, education, income or violence before treatment.

The mean age of the responders was 41.8 (27 to 63). Most of them (67.6\%) had the equivalent of a college education of 12 to 13 years , 27\% had an academic education, 5.4\% had no education after primary school (10 years), $91.9 \%$ lived in a spousal partnership, and 78.3\% were fathers with one to three children $($ Mean $=1.9)$. At the follow-up, $62.9 \%$ lived in the same relationship as before treatment.

\subsection{Treatment Description (Brøsetmodellen)}

The treatment was based on the principles of Aaron Beck's cognitive therapy [5], with a treatment manual constructed by the first author (Jarwson) and colleagues [6] [7] In the first session, anger was described in terms of emotional, psychological, cognitive, and behavioral components.

The first aspect concerned the client-therapist relationship where the therapists reassures the clients that they 
were meeting with respect, warmth, and as "equal human beings". The second aspect of the individual sessions concerned the mutual assessment of the violence problem, creating a shared picture of the problem. Here the CTS assessments were part of the sessions. A third aspect of these individual sessions was reflections on the client's readiness to change, with emphasis on the client's acknowledgement of personal responsibility for his own behavior. If the client and his partner wished, a fourth session with them together reflecting on these themes was offered.

The cognitive group treatment approach combines a variety of techniques such as identifying core beliefs and assumptions that lead to misinterpretation of potentially violent situations. Also important is awareness of situational triggers leading to anger arousal. This may be followed by the patient learning to reframe the angerarousing situation by rehearsing self-instructions. Self-instructions means that the person, when identifying negative thoughts in a situation, tells himself: "Stop! I am overreacting. This is my core belief and vulnerability talking” or "I can handle it. It is not his/her intention to hurt me.” By identifying situational triggers and negative thoughts and feelings, the person may learn to react in a manner appropriate to the situation and avoid using violence.

The group therapy consisted of two equal parts (Table 1).

All sessions are guided by a manual, delivered by qualified therapists to a group of six to eight clients. Each session is of approximately 2 hours in duration.

Table 1. Preparatory and treatment phase of Brøsetmodellen.

\begin{tabular}{|c|c|}
\hline Phase & Session focus \\
\hline \multirow[t]{2}{*}{$\begin{array}{l}\text { Individual therapy } \\
\quad 3 \text { - } 4 \text { hours }\end{array}$} & $\begin{array}{l}\text { Recognizing motivation/readiness for change. } \\
\text { In the individual sessions, the client learns the rationale of the method and the tools used in the group session. } \\
\text { Measures schemas. }\end{array}$ \\
\hline & Group therapy \\
\hline $\begin{array}{l}\text { Session } 1 . \\
\text { psycho-educative }\end{array}$ & $\begin{array}{l}\text { Overview of the group and group rules } \\
\text { Each participant's goal, expectations of the group } \\
\text { What makes people angry into context with other emotions }\end{array}$ \\
\hline $\begin{array}{c}\text { Session } 2 \\
\text { psycho-educative }\end{array}$ & $\begin{array}{l}\text { Anger is an emotion and aggression is a behavior } \\
\text { Event > distressed > "wronged" > anger > mobilized to attack } \\
\text { Learn to gain control over anger through anger circle } \\
\text { Reactions to triggers, thoughts, feelings, arousal, and behavior }\end{array}$ \\
\hline $\begin{array}{c}\text { Session } 3 \\
\text { psycho-educative }\end{array}$ & $\begin{array}{l}\text { The vulnerable self-image and self-esteem. } \\
\text { Awareness of the vulnerability of negative thoughts, how the body reacts. } \\
\text { Alternative coping strategies, time-out, yellow cards. } \\
\text { Alternative thinking errors } \\
\text { (Mindfulness shift focus) }\end{array}$ \\
\hline $\begin{array}{c}\text { Session } 4 \\
\text { psycho-educative }\end{array}$ & $\begin{array}{l}\text { Anger and violence in the family perspective, compassion, respect and cooperation in relationships } \\
\text { Children perspective }\end{array}$ \\
\hline $\begin{array}{l}\text { Session } 5 \\
\text { psycho-educative }\end{array}$ & $\begin{array}{l}\text { Understanding automatic thoughts and learning about core beliefs and underlying beliefs } \\
\text { Identifying the meaning of the event and our perceptions. }\end{array}$ \\
\hline $\begin{array}{l}\text { Session } 6-12 \\
\text { Group therapy }\end{array}$ & $\begin{array}{l}\text { Each client describes how the week has passed with regard to his violent behavior. } \\
\text { Each client has to analyze his violent episode through the cognitive tools. } \\
\text { Event }>\text { negative thoughts > interpretation }>\text { feeling }>\text { arousal }>\text { action. } \\
\text { Using Socratic questions, the therapists encourage the clients to come up with constructive alternatives of } \\
\text { behavior. } \\
\text { The rest of the group participates by helping the client to define an acceptable alternative behavior. }\end{array}$ \\
\hline $\begin{array}{l}\text { Session } 13 \text { - } 14 \\
\text { Group therapy }\end{array}$ & $\begin{array}{l}\text { Understand their own core beliefs in order to recognize them, question them, and acquire techniques for } \\
\text { challenging them. } \\
\text { Cognitive distortions forming core beliefs and ways of addressing them are identified by using rehearsal and } \\
\text { homework }\end{array}$ \\
\hline $\begin{array}{c}\text { Session } 15 \\
\text { Group therapy }\end{array}$ & Group members evaluate each other and identify areas where they need to be cautious in the future. \\
\hline
\end{tabular}




\subsection{Measures}

Data on violence were collected before and four to seven years after treatment using a modified version of the Conflict Tactic Scale, CTS [8]. The CTS has been the principal method of measuring physical aggression among community samples of married couples or individuals dating. The CTS consists of a list of actions that a family member might use when in conflict with another family member, a friend or a stranger. The original CTS is intended to measure three constructs: Reasoning, Verbal Aggression, and Physical Aggression or Violence. In this study, the "reasoning" items from the CTS were dropped, and a section on material and sexual violence was added.

Clients who participated in the follow-up study answered the same CTS schema, and they registered the anger and violence throughout the previous year.

In this study, domestic violence is defined as the use of physical, psychological, or material violence by one adult towards a member of the household to cause harm, injury, or fear. Physical violence items involve throwing something, pushing, grabbing, shoving, slapping, spanking, kicking, biting, punching, hitting, or trying to hit with an object, beating, choking, threatening with weapons like a knife or a gun, and using weapons like a knife or a gun.

Psychological violence involves interrogating a partner when she has been out, calling her obscene names, or frightening her with threatening body language in intense jealousy. "Verbal Aggression” also means shouting at her, using verbal and symbolic means of hurting, such as insults or threats. Material violence was defined as behaviors such as pounding the wall or table as well as destroying property.

The violent acts were registered on a response scale with the options one, two, three times or more during the year.

The follow up questionnaire also focused on the target content of the intervention and asked ten questions concerning the use of crucial cognitive techniques in "the Brøset model” of anger management treatment [9]. The items were scored on a five-point ordinal rating scale reporting the frequency of utilization: 1 ("never”), 2 ("once"), 3 ("two to five times"), 4 ("six to ten times") and 5 ("more than ten times"). In the further analysis, categories 2 and 3 were combined into the new category "sometimes", and categories 4 and 5 were combined into the new category "frequently".

\subsection{Ethics}

The study was approved by the Regional Committee for Research Ethics (REK) and the Norwegian Data Inspectorate (NSD).

\section{Results}

The overall results showed that there was a decrease in physical and psychological violence at the follow up, four to seven years after treatment.

Physical violence and psychological violence were described in $70.3 \%$ and in $89.2 \%$ of the responders $(\mathrm{N}=$ 37) before treatment. Most participant (83.8\%) reported a termination of physical violence at the follow-up, $10.8 \%$ were still physically violent and $5.4 \%$ were more physically violent four to seven years after treatment completion. A majority of the participants (59.4\%) reported a termination of their use of psychological violence at follow-up, 32.4\% were still psychologically violent, and 8.1\% reported more psychologically violent behavior (see Figure 1).

The decrease in physical violence was statistically significant: $t(36)=8.43$, $p<0.001$ with a large effect size (eta squared $=0.66$ ). Psychological violence also decreased significantly: $t(36)=9.21, p<0.001$ with a large effect size (eta squared $=0.7$ ).

The results indicated that the most important anger management techniques were extensively applied in patients of the previous anger management treatment program. In total, about two out of three patients still used the techniques after ending treatment four to seven years earlier. The anger management circle was less used compared to the "time-out” techniques, recognizing body signals and anger management openness (Q9), but all techniques significantly approached in the patients repertoire (see Table 2).

A Friedman's Two-Way analysis of Variance by Ranks was conducted to evaluate the differences in frequency of using anger management techniques. A statistically significant difference between reports of "never 


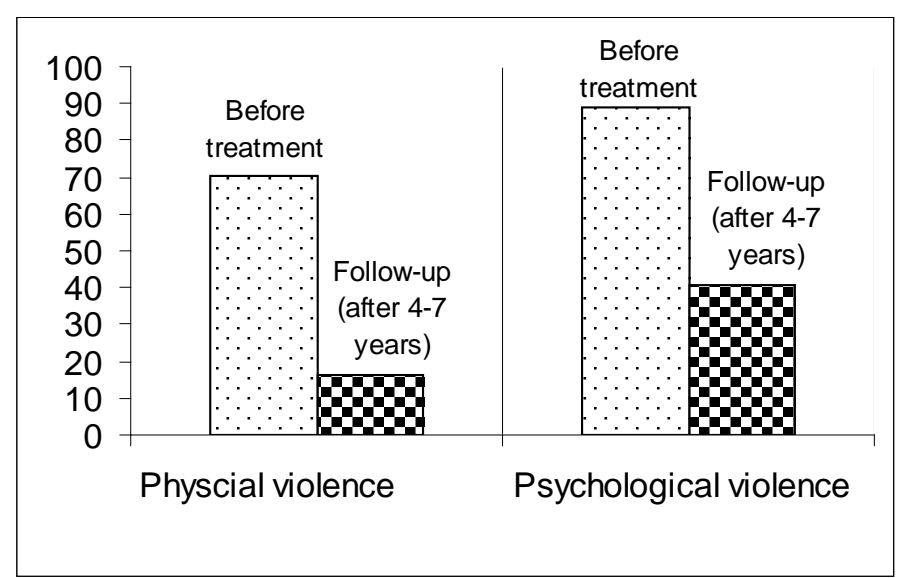

Figure 1. Self-reported violence before and at follow-up treatment.

Table 2. The frequency of using anger management techniques in all the patients $(n=37)$ and in patients with a self-reported positive treatment outcome.

\begin{tabular}{|c|c|c|c|}
\hline Anger management technique & $\begin{array}{l}\text { Frequently used in } \\
\text { all patients }(\mathrm{n}=37)\end{array}$ & $\begin{array}{l}\text { Frequently used in } \\
\text { non-physical violent patients } \\
\qquad(\mathrm{n}=31)\end{array}$ & $\begin{array}{l}\text { Frequently used in } \\
\text { non-psychological violent } \\
\text { patients }(\mathrm{n}=22)\end{array}$ \\
\hline Q1: circle of anger & 15 & 13 & 10 \\
\hline Q2: “time-out” techniques & 26 & 23 & 13 \\
\hline Q3: Recognizing body signals & 25 & 23 & 14 \\
\hline Q4: Recognizing negative thoughts & 23 & 21 & 15 \\
\hline Q5: Stop, making thought controlled & 24 & 20 & 16 \\
\hline Q6: Evaluating missing interpretation & 23 & 21 & 13 \\
\hline $\begin{array}{l}\text { Q7: Evaluating the situation based on } \\
\text { life-rules (expectations) }\end{array}$ & 21 & 20 & 12 \\
\hline $\begin{array}{l}\text { Q8: Take the responsibility of acting calm } \\
\text { when humiliated }\end{array}$ & 21 & 19 & 13 \\
\hline Q9: Discussing your anger problem & 26 & 23 & 16 \\
\hline $\begin{array}{l}\text { Q10: Focusing the self-confidence of } \\
\text { acting without violence }\end{array}$ & 26 & 22 & 15 \\
\hline Q11: Self-confidence avoiding violence & 19 & 18 & 12 \\
\hline Mean number of techniques used & $6.7(\mathrm{sd}=3.4)$ & $7.2(\mathrm{sd}=3.3)$ & $6.8(\mathrm{sd}=3.8)$ \\
\hline
\end{tabular}

use" $($ Median $=14.1)$, "sometimes use" $($ Median $=19.8)$ and reports of "frequently use" $[$ Median $=66.2, \mathrm{p}<$ $0.001]$ arose.

\section{Discussion}

The results of the study of 37 former patients showed that a 15-week group-based anger management CBT program significantly reduced self-reported violent behavior. Further analysis showed that a number of anger management techniques that were emphasized in the program were substantially applied four to seven years after the treatment. Most participants reported applying several anger management techniques on a frequent basis. This result may be associated with the general decrease in self-reported spousal violence compared to the frequency of violent actions before the program. Timeout, recognizing body signals and negative thoughts, and discussing one's anger problem seemed most prominent among the tools they used. A balance of implicit and explicit techniques was emphasized in the group treatment, and the report was promising since in more than two out of three 
participants four to seven years after treatment, the former clients still frequently used these techniques. The relatively less frequent use of the "anger management circle" may indicate that an integrated comprehension of anger management belongs to an advanced level, but it is not necessarily useful to all patients. Few or no long-term follow-up studies exist on the effects of this type of treatment [2].

Additionally, few or no studies exist that investigate what motivates abusive men to stay in treatment. This fact makes interesting that all the men who started in the group sessions in our study also completed the program. The high completion rate among our subjects may seem out of the ordinary in view of other studies finding that non-court ordered men attend fewer sessions than court-ordered [10] [11].

These findings indicate that the treatment as a whole, including the initial individual sessions, was effective by itself, and also that it had effects over a long time span after treatment. Since 1960, Cognitive Therapy (CT) and Cognitive Behavioral Therapy (CBT), and programs with elements of CBT, such as the Duluth Model (Domestic Abuse Intervention Project DAIP, 1981), have frequently been used as treatment for men who abuse their female partners. The Duluth Model reflects the underlying feminist philosophy that violence is used by men to exert "power and control" over the behavior of their female partners. In recent years, the Duluth Model has been criticized for its lack of scientific research and for being impeded by the feminist ideological structure inherent in the patriarchal view of "power and control" [12]. Dutton and Corvo stated that men in treatment groups were more often characterized by powerlessness than by power and that the concept of power was misused by feminists.

The "Brøset Model" has a conventional Cognitive Therapy for anger as conceptualized by Beck [5] [13], working with automatic thoughts, logical errors, cognitive distortions, and core beliefs [14]. In the CBT group, self-disclosure is necessary for the group to gain access to covert cognitive processes that represent potential treatment targets. Feedback from the group, as well as the therapists, plays a role in helping to shift patients' distorted cognition and to reinforce more realistic appraisals.

Another important aspect is a therapeutic relationship built on warmth, empathy, and Socratic dialogue. This is in contrast to the moralistic attitude in CBT programs that has components from the Duluth Model [2]. The previous report [4] showed that a 15-week manual, group-based CBT program significantly and substantially reduced self-reported violent behavior at the end of treatment.

This follow up study on the Brøset Model four to seven years after treatment has some limitations, based on the small sample size and the lack of a control group.

Despite the methodological limitations of the response rate bias that self-reports represent, and the social desirability bias, the findings reported are interesting and important in their own right. Even four to seven years after treatment, when these men felt angry, many used the techniques they had learned to calm themselves down and consequently avoided violent situations. The skill-based training that was emphasized in the anger management program described above seemed to be an important and feasible element of the treatment many years after. This may indicate that being aware of bodily signs and negative thoughts when one is angry and-maybe most importantly - learning alternative ways to handle these situations, are potential moderating factors in the treatment of domestic perpetrators. The results in this study indicate that despite experiencing anger arousal, men can avoid acting out the anger if they receive the right tools to handle the angry feelings.

Controlled studies involving partner interviews and the separate techniques' impact may provide information on effective components of the improved treatment model.

\section{References}

[1] Gondolf, E.W. and Jones, A.S. (2001) The Program Effect of Batterer Programs in Three Cities. Violence and Victims, 16, 693-704.

[2] Smedslund, G., et al. (2007) Cognitive Behavioral Therapy for Men Who Physically Abuse Their Female Partner. The Cochrane Library, JohnWiley \& Sons, Ltd., Hoboken.

[3] Beck, R. and Fernandez, E. (1998) Cognitive-Behavioral Therapy in the Treatment of Anger: A Meta-Analysis. Cognitive Therapy and Research, 22, 63-74. http://dx.doi.org/10.1023/A:1018763902991

[4] Palmstierna, T., et al. (2012) Cognitive-Behavior Group Therapy for Men Voluntary Seeking Help for Intimate Partner Violence. Nordic Journal of Psychiatry, 66, 360-365. http://dx.doi.org/10.3109/08039488.2012.665080

[5] Beck, A.T. (1999) Prisoners of Hate: The Cognitive Basis of Anger, Hostility, and Violence. Harper Collins Publishers, New York. 
[6] Haugan, G. and Jarwson, S. (2005) Kognitiv terapi ved vold og aggresjon [Cognitive Therapy of Violence and Aggression]. Tidsskrift for kognitiv terapi, 6, 1-10.

[7] Jarwson, S. and Haugan, G. (2008) Violence and Anger: A Treatment Manual in Anger. In: Berge, T. and Repål, A., Eds., Håndbok i kognitiv terapi, Gyldendal Norsk forlag, Oslo, 349-378.

[8] Straus, M.A. (1979) Measuring Intrafamily Conflict and Violence: The Conflict Tactics (CT) Scales. Journal of Marriage and the Family, 41, 75-88. http://dx.doi.org/10.2307/351733

[9] Jarwson, S. (2010) Effekten av manualisert kognitiv gruppeterapi for menn som frivillig søker hjelp mot vold i nære relasjoner: Effekten av kognitiv gruppeterapi etter deltakelse i Sinnemestring Brøsetmodellen 4-7 år etter avsluttet terapi.

[10] Daly, J.E., Power, T.G. and Gondolf, E.W. (2001) Predictors of Batterer Program Attendance. Journal of Interpersonal Violence, 16, 971-991. http://dx.doi.org/10.1177/088626001016010001

[11] Gerlock, A.A. (2001) A Profile of Who Completes and Who Drops Out of Domestic Violence Rehabilitation. Issues in Mental Health Nursing, 22, 379-400. http://dx.doi.org/10.1080/01612840116997

[12] Dutton, D.G. and Corvo, K. (2006) Transforming a Flawed Policy: A Call to Revive Psychology and Science in Domestic Violence Research and Practice. Aggression and Violent Behavior, 11, 457-483. http://dx.doi.org/10.1016/j.avb.2006.01.007

[13] Beck, A.T. (1979) Cognitive Therapy and the Emotional Disorders. International Universities Press, New York.

[14] Young, J.E., Klosko, J.S. and Weishaar, M.E. (2003) Schema Therapy: A Practitioner’s Guide. Guilford Press, New York. 